\title{
Behaviour of coupling beams having vertical slits at the ends
}

\author{
S. B. Yuksel \\ Department of Civil Engineering, Selcuk University, Turkey
}

\begin{abstract}
Architectural considerations and functional use result in door openings on the shear walls of tunnel form buildings, which cause coupled shear walls to be connected by short, deep and thin coupling beams. These coupling beams are subjected to higher shear forces and their thickness becomes generally less than $250 \mathrm{~mm}$ for the tunnel form buildings, and much less than their counterparts in conventional reinforced concrete structures. It is simply not possible to design practically constructible coupling beams in the tunnel form buildings. In a coupled shear wall system, shear forces acting on the coupling beams can be reduced simply by the application of vertical separation joints (slits) at the ends of the coupling beams. As a design alternative, the use of slit connections at the ends of the coupling beams to be able to decrease the shear stiffness and shear forces was analytically investigated. Shear stiffness terms of common slit connected coupling beams (SCCBs) were derived by using plane stress finite elements. To be specific, extensive parametric study with respect to the geometry of a SCCB was carried out. Coupling beam heights, coupling beam lengths, slit heights and slit lengths were varied in an extensive parametric study to demonstrate their influences on the shear stiffness terms.

Keywords: coupling beams, coupled shear walls, finite element analysis, nonprismatic members, tunnel form buildings.
\end{abstract}

\section{Introduction}

Tunnel form (shear wall dominant) building system is an industrialized construction technique in which structural walls and slabs of the building are cast in one operation by using steel forms having accurate dimensions and plain surfaces [1]. In tunnel form construction, in situ concrete is poured into two half- 
tunnel forms to form shear walls and floor slabs simultaneously [2]. When this process is repeated, usually in a $24 \mathrm{hr}$ cycle per floor, the residential units can be created with great rapidity. In general, all the floor plans become the same due to the same steel tunnel forms being utilized in all of the stories. A typical tunnel form system and its site applications are demonstrated in fig. 1 .

Shear walls act as the primary gravity and lateral load carrying members, and may contain openings for functional use in tunnel form buildings. The sizes of the openings are determined by the functional use and the architectural restrictions on the shear walls; the dimensions of the coupling beams are defined in that way. The geometric limits result in deeper coupling beams in relation to their clear span above the door openings, and the thickness of these coupling beams are usually less than $250 \mathrm{~mm}$ for the tunnel form buildings as can be seen in fig. 2. The dimensional constraints and high shear forces acting on these beams cause their design to become almost impossible according to the code specified reinforcement configurations.
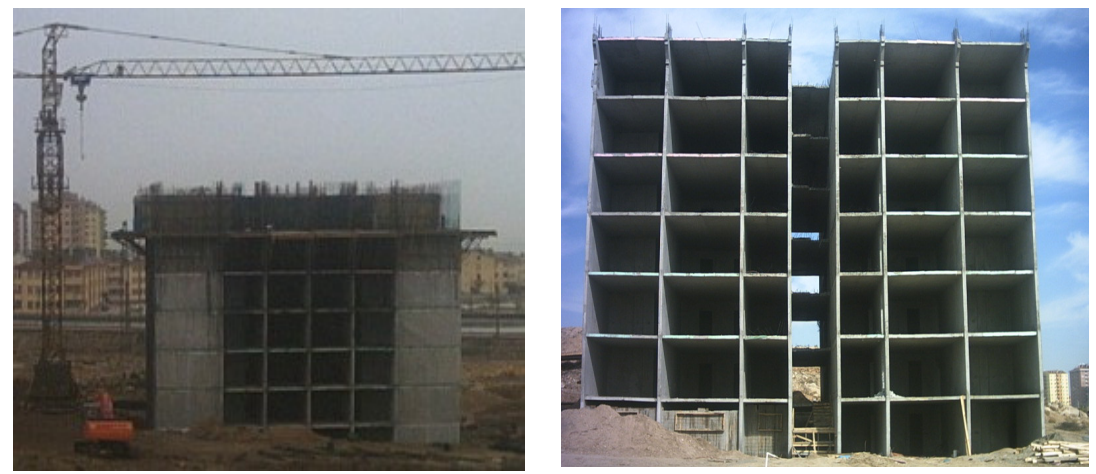

Figure 1: $\quad$ Typical tunnel form systems at construction stage.
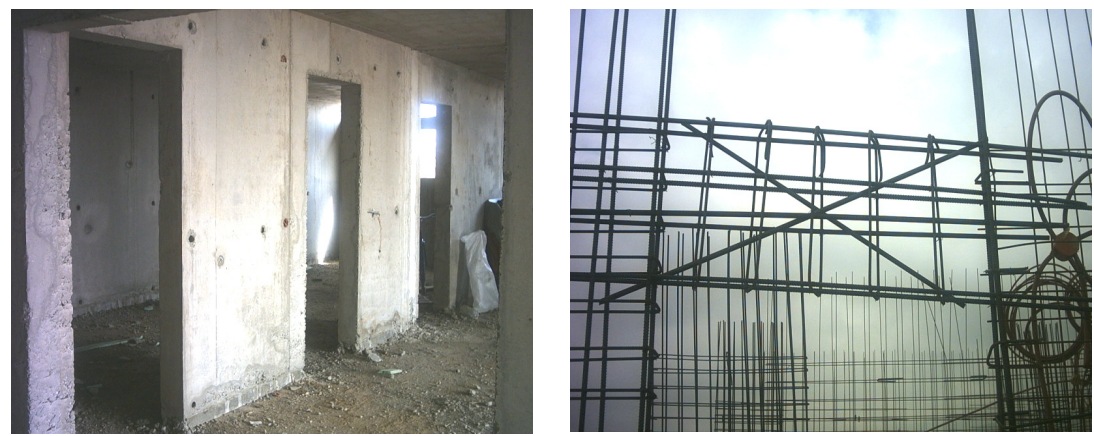

Figure 2: $\quad$ Typical deep coupling beams above the door opening and diagonal reinforcement without confining ties in a tunnel form building. 
Coupling beams in tunnel form buildings are susceptible to high shear forces due to dimensional constraints. Although using the code specified diagonal layout with confining ties [3,4] for the coupling beams of tunnel form buildings seems to be a solution, this detailing is generally avoided in practice (see fig. 2) due to constructional difficulties. Serious problems with construction and difficulties in manufacturing can occur during the application of diagonal layout with confining ties when the thickness of the wall is less than $250 \mathrm{~mm}$. Until now, the practical design application of thin coupling beams of tunnel form building structures has been limited.

As a design alternative, shear forces in coupling beams can be decreased by introducing vertical separation joints (slits) at each ends of coupling beams without violating the architectural requirements and functional use. Yuksel [5] performed more than 800 static and dynamic finite element analyses on 240 different coupled shear walls with SCCBs having different stories, to be able to generalize the seismic behavior of the coupled shear walls with SCCBs. The internal force distribution, the overall stiffness and the dynamic behavior of the coupled shear walls with SCCBs were investigated and it was proven that the shear forces in deep coupling beams decrease significantly due to the existence of slits at the ends.

The objective of this paper is to present the behavior of SCCBs with the aid of the finite element method. Parametric studies are performed to investigate the shear stiffness factors of SCCBs. The effects of slits due to their application at the ends of the coupling beams are investigated for typical SCCBs. Unless the detailed finite element modeling is utilized, the conventional methods become deficient to compute the stiffness factors due to abrupt change in the centroidal axis associated with the non-prismatic section (see fig. 3). Despite the robustness of the finite element modeling, the generation of the fixed-end forces from the nodal outputs of the detailed mesh still remains as an intricate task.

\section{Application of vertical separation joints to reduce the shear stiffness of the coupling beams}

The dimensions of the coupling beams are the effective parameters on the behavior of the coupled shear walls when they are subjected to lateral loads [68]. In particular, the coupled shear walls will react to the lateral loads due to the stiffness ratio of the coupling beams to the shear walls [9]. Apparently, reducing the height of the coupling beam section will decrease its stiffness and result in a diminishing effect on the internal shear forces of the coupling beams, yet there are generally height constraints for the coupling beams due to the architectural restrictions and functional use. However, the shear stiffness and the internal shear forces of the deep coupling beams can be reduced by introducing slits without changing the dimensions of the coupling beams and not violating the architectural and functional requirements. It is proven that the use of the vertical slits at the ends of the coupling beams potentially reduces the higher shear forces acting on these coupling beams [5]. 


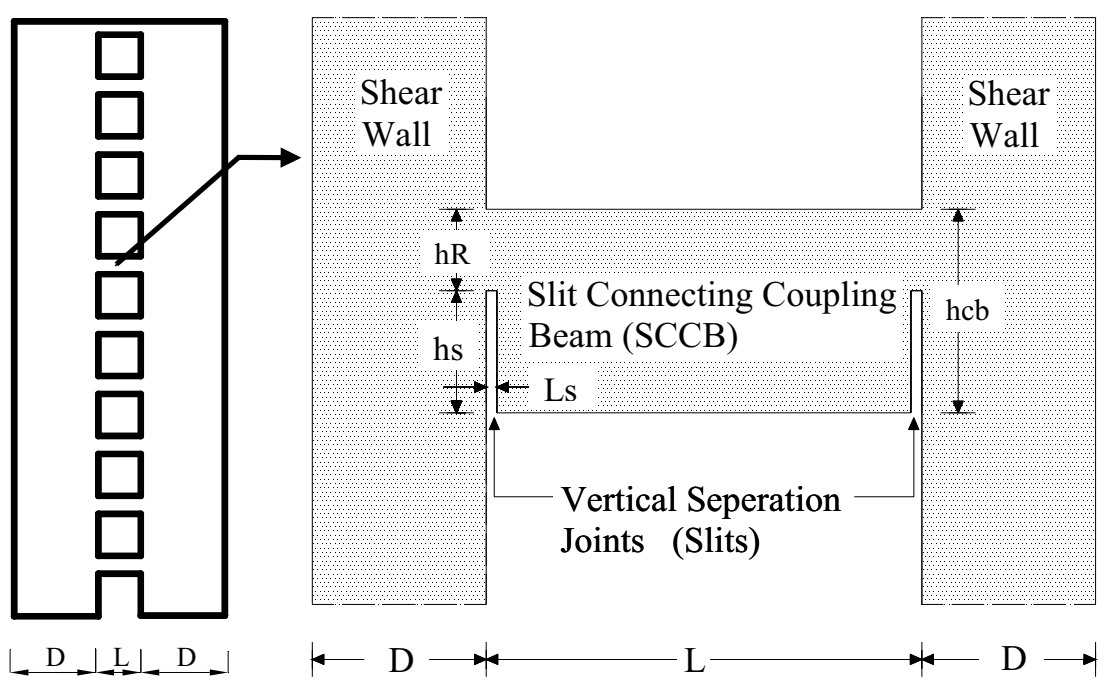

Figure 3: Application of slits at the ends of the coupling beams for coupled shear walls and the details of the slit connected coupling beams.

SCCBs can be classified as the special non-prismatic beams with varying slit heights and slit lengths at their ends. The geometric parameters of typical SCCBs are presented in fig. 3 , where; $h_{c b}=$ height of the coupling beam, $L=$ length of the coupling beam, $h_{s}=$ slit height at the beam-wall connections, $\mathrm{L}_{\mathrm{s}}=$ slit length at the beam-wall connections, $\mathrm{h}_{\mathrm{R}}=$ height of the coupling beam at the beam-wall connections, $\mathrm{D}=$ length of the individual shear walls forming the coupled shear wall system, $\mathrm{b}=$ shear wall or coupling beam thickness. Slit height ratio is defined as the ratio of the slit height to the total height of the coupling beam $(\mathrm{S}=$ $\left.\mathrm{h}_{\mathrm{s}} / \mathrm{h}_{\mathrm{cb}}\right)$. Slit length ratio is the ratio of the slit length to the coupling beam length $\left(\alpha=\mathrm{L}_{\mathrm{s}} / \mathrm{L}\right)$.

\section{Parametric study and the finite element modelling of SCCBs}

Coupling beams with symmetrical slits at their ends shown in fig. 3 are generated as the model structures for the analysis. Whole parts of the SCCBs were modeled using four-node shell elements with two translational degrees of freedom (d.o.f.) and one rotational d.o.f. per node. In order to have adequate accuracy, SCCBs were modeled using shell elements with dimensions of $10 \mathrm{~mm} \times 10 \mathrm{~mm}$. The SAP2000 computer program [10] was used to develop the finite element models of the typical coupling beams with symmetrical vertical slits at their ends. A typical finite element model of SCCBs (given $b=0.2 \mathrm{~m}$, $\mathrm{h}_{\mathrm{cb}}=0.9 \mathrm{~m}, \mathrm{~L}=1 \mathrm{~m}$ ) having the slit height of $450 \mathrm{~mm}$ and slit length of $40 \mathrm{~mm}$ was formed with 8560 shell elements and is shown at the left side of the fig. 4 . The deflected shape of the same SCCB due to a vertical unit displacement at the left 
end is illustrated in the right side of the fig. 4 for the shear stiffness analysis. In finite element analyses, the vertical unit displacements are represented by a set of prescribed nodal displacements [11]. Since the computation of the stress values or nodal forces is not sufficient for the calculation of the stiffness terms, the shear stiffness terms of SCCBs were calculated by using the nodal force outputs of the finite element analysis proposed by Bathe [12] and discussed in Horrowitz [13].
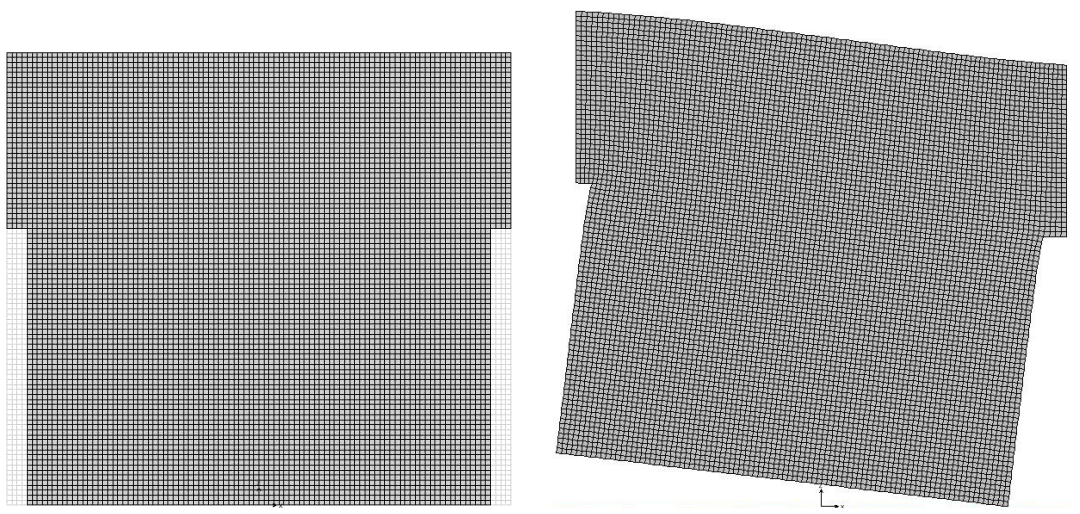

Figure 4: A typical finite element model of a SCCB using 8560 shell elements and its deflected shape due to vertical unit displacement at the left, while all other d.o.f.s are held for shear stiffness analysis.

In practice, the coupling beams above the door openings of the tunnel form buildings are generally constructed with $0.7 \sim 0.9 \mathrm{~m}$ heights and $0.8 \sim 1.2 \mathrm{~m}$ lengths for functional use and architectural considerations. The thickness of these coupling beams is generally less than $250 \mathrm{~mm}$ for tunnel form buildings. For actual modeling, while the length of the coupling beams were varied as $0.8 \mathrm{~m}$, $0.9 \mathrm{~m}, 1.0 \mathrm{~m}, 1.1 \mathrm{~m}, 1.2 \mathrm{~m}$, the thickness of the shear wall and the coupling beam was taken as the constant value of $0.2 \mathrm{~m}$. The depth of the coupling beams was taken as $0.75 \mathrm{~m}$ and $0.90 \mathrm{~m}$ for the parametric studies. The dimensions of the cross sections of the shear walls and the coupling beams are consistent with practical applications. The compressive strength of concrete was assumed to be $25 \mathrm{MPa}$. The modulus of elasticity (E) and the Poisson's ratio (v) were taken as $3 \times 10^{7} \mathrm{kN} / \mathrm{m}^{2}$ and 0.2 respectively for all the analyses.

The slit heights $\left(\mathrm{h}_{\mathrm{s}}=0.0 \mathrm{~m}, 50 \mathrm{~mm}, 100 \mathrm{~mm}, 150 \mathrm{~mm}\right.$, etc $)$ and the slit lengths $\left(\mathrm{L}_{\mathrm{s}}=0.0 \mathrm{~mm}, 10 \mathrm{~mm}, 20 \mathrm{~mm}, 30 \mathrm{~mm}, 40 \mathrm{~mm}\right.$ and $\left.50 \mathrm{~mm}\right)$ were changed to achieve the values of the parameters, and the slab thickness was taken as $0.10 \mathrm{~m}$ for all the analyses. Since the slits can only be extended up to the bottom of the floor slab whose thickness is taken as $0.10 \mathrm{~m}$, the maximum slit height can be $0.65 \mathrm{~m}$ $(\mathrm{S}=0.866)$ and $0.80 \mathrm{~m}(\mathrm{~S}=0.888)$ for $0.75 \mathrm{~m}$ and $0.90 \mathrm{~m}$ coupling beam heights, respectively. For each case, the vertical unit displacement was applied to each SCCBs to be able to determine the shear stiffness terms, and the outputs of finite element analysis results were scanned to compute the shear stiffness terms. 


\section{Effect of slits on the shear stiffness terms of coupling beams}

The coupling beams that are deep in relation to their clear span undergo significant shear deformations. Thus, the effect of shear deformation in deep coupling beams is of greater importance than in conventional beams. Many classical books on structural analysis [14] give the stiffness influence coefficients of a prismatic beam element including transverse shear deformation. The shear stiffness term is expressed as in eqn. (1).

$$
\mathrm{k}_{11}=\frac{1}{1+2 \mathrm{~g}} \times \frac{12 \mathrm{EI}}{\mathrm{L}^{3}}
$$

where $\mathrm{E}$ is the modulus of elasticity of the material, $\mathrm{I}$ is the gross moment of inertia of the section about the bending axis, $\mathrm{L}$ is the beam length, $\mathrm{g}$ is the dimensionless shear constant defined as $\mathrm{g}=(6 \mathrm{fEIG}) /\left(\mathrm{GAL}^{2}\right), \mathrm{f}$ is the shape factor (1.2 for rectangular cross sections), $\mathrm{G}$ is the shear modulus of the material and $\mathrm{A}$ is the cross sectional area of the beam section. Because a SCCB is non-prismatic, eqn. (1) does not accurately represent its shear stiffness. A detailed analysis is carried out to determine the magnitude of the reductions made on the shear stiffness terms in the presence of vertical separation joints of various slit height ratios, slit length ratios, coupling beam lengths and coupling beam heights. The shear stiffness term of a beam element is the shear force required to produce a vertical unit displacement at one end while all other d.o.f.s are set to zero (see fig. 4). The effect of shear deformations was taken into account in deriving the stiffness terms of SCCBs.

The shear stiffness terms including transverse shear deformations of coupling beams without any slits are calculated for different coupling beam lengths by using eqn. (1). The values obtained by eqn. (1) are compared with those obtained by the finite element analyses. The comparisons present better agreement with the maximum observed deviation of $3.9 \%$ for the shear stiffness term of the coupling beam having the length of $0.8 \mathrm{~m}$. The deviation in the stiffness terms decreases as the coupling beam heights decrease or the coupling beam lengths increase.

The effect of slit heights on the shear stiffness term (given as $b=0.2 \mathrm{~m}$ and $\mathrm{h}_{\mathrm{cb}}$ $=0.90 \mathrm{~m})$ is presented in the left graph of fig. 5 for different coupling beam lengths $(\mathrm{L}=0.8 \mathrm{~m}, 0.9 \mathrm{~m}, 1.0 \mathrm{~m}, 1.1 \mathrm{~m}, 1.2 \mathrm{~m})$. The slit height has a significant effect on the reduction of the stiffness terms of the coupling beams. For a given specific coupling beam length, as the height of the slits increases, the reduction in the shear stiffness terms increases at an increasing rate. The relationship between the slit height ratio and the reduction in shear stiffness terms is nonlinear. A typical plot of the shear stiffness terms of SCCBs (given as $b=0.2 \mathrm{~m}$ and $\mathrm{h}_{\mathrm{cb}}=0.90 \mathrm{~m}$ ) versus the slit height ratios is presented in the right graph of fig. 5 for different slit lengths $\left(\mathrm{L}_{\mathrm{s}}=0 \mathrm{~mm}, 10 \mathrm{~mm}, 20 \mathrm{~mm}, 30 \mathrm{~mm}, 40 \mathrm{~mm}\right.$ and $50 \mathrm{~mm})$. However, it should be noted that, for a given specific coupling beam length and slit height, as the length of the slits increases, the reduction in shear stiffness terms increases. The decrease in shear stiffness terms according to the 
slit lengths is in negligible level. Fig. 6 represents the variation of the shear stiffness terms (the cross sectional dimension is given as $0.2 \mathrm{~m} \times 0.75 \mathrm{~m}$ ) as the functions of slit heights for $0.8 \mathrm{~m}$ and $1 \mathrm{~m}$ lengths of SCCBs where the slit lengths vary $\left(\mathrm{L}_{\mathrm{s}}=0 \mathrm{~mm}, 10 \mathrm{~mm}, 20 \mathrm{~mm}, 30 \mathrm{~mm}, 40 \mathrm{~mm}\right.$ and $\left.50 \mathrm{~mm}\right)$. The decrease in the shear stiffness terms for the given slit height ratios and coupling beam lengths do not change considerably for different coupling beam heights.

The shear stiffness terms of SCCBs $\left(\mathrm{k}_{11(\mathrm{SCCB})}\right)$ are normalized with respect to the shear stiffness terms of the prismatic coupling beams $\left(\mathrm{k}_{11(\mathrm{SCCB})} / \mathrm{k}_{11}\right)$. The shear stiffness terms of the coupling beams without any slit connections $\left(\mathrm{k}_{11}\right)$ are calculated using eqn. (1). Table 1 presents the normalized shear stiffness terms of $1 \mathrm{~m}$ length SCCBs (given $\mathrm{b}=0.2 \mathrm{~m}$ and $\mathrm{h}_{\mathrm{cb}}=0.90 \mathrm{~m}$ ) with respect to slit height ratio $(\mathrm{S})$ for different slit length ratios $(\alpha)$. Also, the normalized shear stiffness terms of SCCBs having dimensions of $b=0.2 \mathrm{~m}$ and $\mathrm{h}_{\mathrm{cb}}=0.90 \mathrm{~m}$ are given in Table 2 with respect to the slit height ratios $(\mathrm{S})$ for different SCCB lengths $(\mathrm{L}=$ $0.8 \mathrm{~m}, 0.9 \mathrm{~m}, 1.0 \mathrm{~m}, 1.1 \mathrm{~m}, 1.2 \mathrm{~m})$. It is proven in Table 1 and Table 2 that the shear stiffness terms for SCCBs are not constant, as they depend on the relation between slit height ratios (S), slit length ratios $(\alpha)$ and the coupling beam lengths (L). The variation of the shear stiffness terms is pronounced more for the slit height ratios than for the slit length ratios and the coupling beam lengths. For a given specific coupling beam length and slit height, as the length of slits increases, the reduction in shear stiffness terms increase in negligible level. The shear stiffness terms for given specific slit heights and slit lengths do not change considerably for different coupling beam lengths.
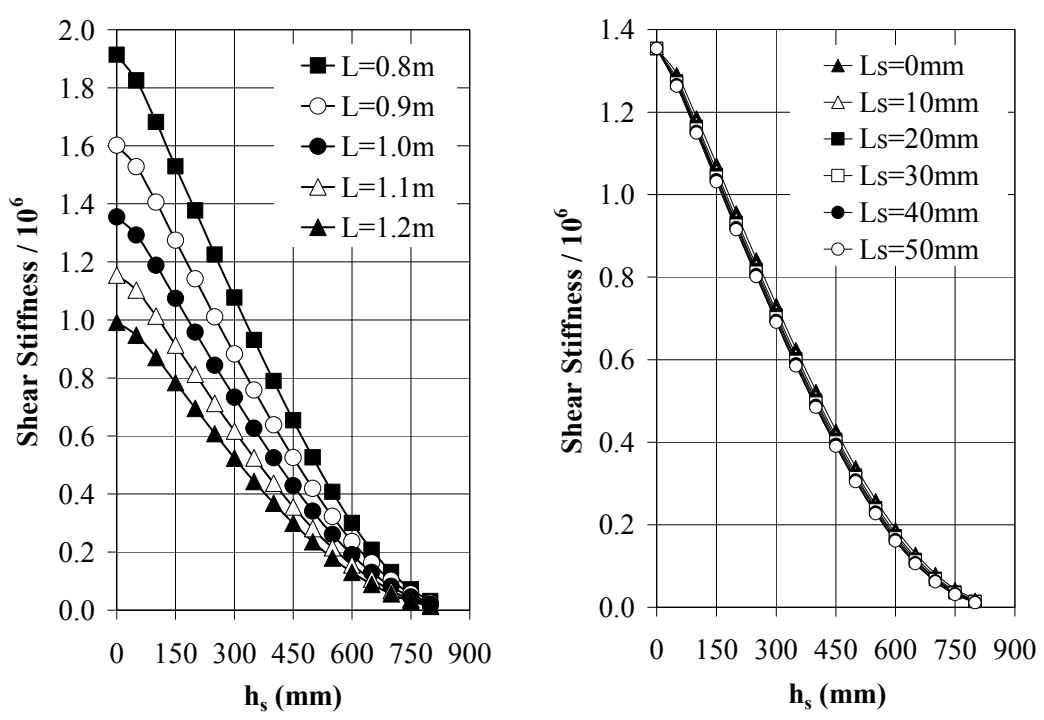

Figure 5: The variation of shear stiffness terms of SCCBs versus slit heights $\left(h_{s}\right)$ for different coupling beam lengths $(L)$ and slit lengths $\left(L_{s}\right)$. 


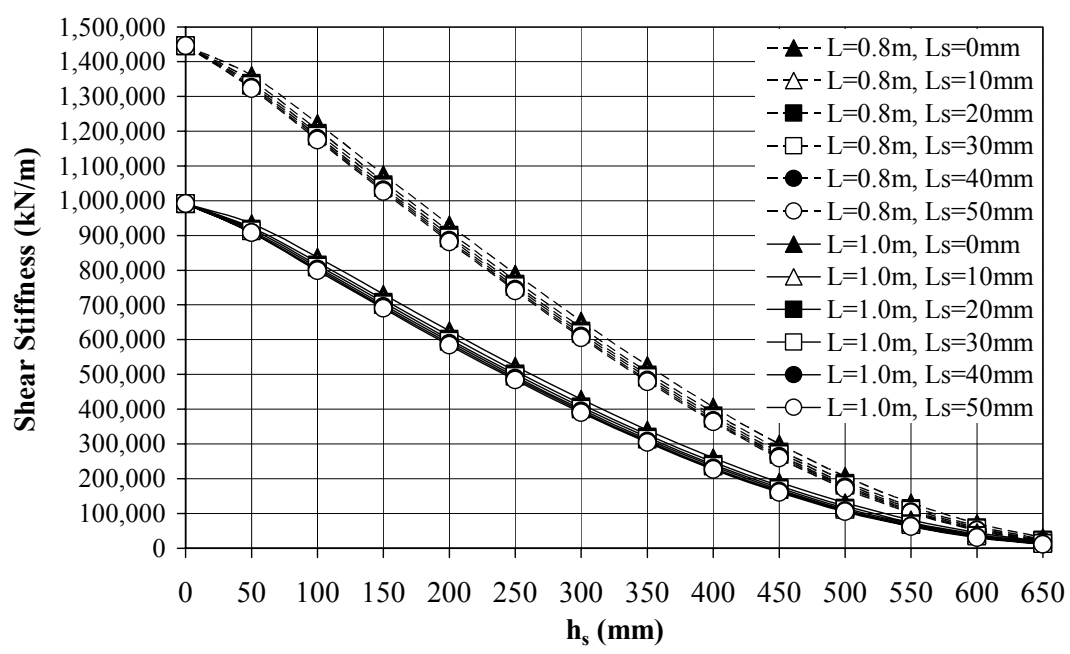

Figure 6: The variation of shear stiffness terms of SCCBs $(b=0.2 \mathrm{~m}$, $\mathrm{h}_{\mathrm{cb}}=0.75 \mathrm{~m}$ ) versus slit heights for different coupling beam lengths and slit lengths.

Table 1: Normalized shear stiffness factors $(\mathrm{k} 11(\mathrm{SCCB}) / \mathrm{k} 11)$ for $1 \mathrm{~m}$ length SCCBs with respect to slit height ratios (S) for different slit length ratios $(\alpha)$.

\begin{tabular}{|c||c|c|c|c|c|c|}
\hline \multicolumn{1}{|c||}{$\mathrm{S}$} & \multicolumn{7}{c|}{$\alpha$ (slit length ratio) } \\
\cline { 2 - 7 } & 0.00 & 0.01 & 0.02 & 0.03 & 0.04 & 0.05 \\
\hline \hline 0.00 & 1.000 & 1.000 & 1.000 & 1.000 & 1.000 & 1.000 \\
\hline 0.06 & 0.955 & 0.946 & 0.942 & 0.938 & 0.935 & 0.933 \\
\hline 0.11 & 0.878 & 0.866 & 0.860 & 0.856 & 0.852 & 0.848 \\
\hline 0.17 & 0.793 & 0.781 & 0.774 & 0.769 & 0.765 & 0.762 \\
\hline 0.22 & 0.707 & 0.695 & 0.689 & 0.684 & 0.679 & 0.676 \\
\hline 0.28 & 0.623 & 0.611 & 0.605 & 0.600 & 0.595 & 0.592 \\
\hline 0.33 & 0.542 & 0.530 & 0.523 & 0.518 & 0.514 & 0.510 \\
\hline 0.39 & 0.463 & 0.451 & 0.445 & 0.440 & 0.435 & 0.432 \\
\hline 0.44 & 0.388 & 0.377 & 0.370 & 0.365 & 0.361 & 0.358 \\
\hline 0.50 & 0.317 & 0.306 & 0.300 & 0.296 & 0.292 & 0.288 \\
\hline 0.56 & 0.252 & 0.242 & 0.236 & 0.232 & 0.228 & 0.225 \\
\hline 0.61 & 0.193 & 0.184 & 0.178 & 0.174 & 0.171 & 0.168 \\
\hline 0.67 & 0.141 & 0.133 & 0.128 & 0.124 & 0.121 & 0.118 \\
\hline 0.72 & 0.096 & 0.090 & 0.086 & 0.083 & 0.080 & 0.078 \\
\hline 0.78 & 0.061 & 0.055 & 0.052 & 0.049 & 0.047 & 0.046 \\
\hline 0.83 & 0.033 & 0.029 & 0.027 & 0.025 & 0.024 & 0.023 \\
\hline 0.89 & 0.014 & 0.012 & 0.011 & 0.010 & 0.009 & 0.008 \\
\hline
\end{tabular}


Table 2: $\quad$ Normalized shear stiffness factors (k11(SCCB) / k11) for SCCBs having cross sectional dimensions of $b=0.2 \mathrm{~m}$ and $0.9 \mathrm{~m}$ with respect to slit height ratios $(\mathrm{S})$ for different SCCB lengths (L).

\begin{tabular}{|c||c|c|c|c|c|}
\hline \multicolumn{6}{|c|}{$\mathrm{k}_{11(\mathrm{SCCB})} / \mathrm{k}_{11}$} \\
\hline \hline \multirow{2}{*}{$\mathrm{S}$} & \multicolumn{5}{c|}{$\mathrm{L}$} \\
\cline { 2 - 6 } & $0.8 \mathrm{~m}$ & $0.9 \mathrm{~m}$ & $1.0 \mathrm{~m}$ & $1.1 \mathrm{~m}$ & $1.2 \mathrm{~m}$ \\
\hline \hline 0.00 & 1.000 & 1.000 & 1.000 & 1.000 & 1.000 \\
\hline 0.06 & 0.955 & 0.955 & 0.955 & 0.955 & 0.955 \\
\hline 0.11 & 0.879 & 0.878 & 0.878 & 0.878 & 0.878 \\
\hline 0.17 & 0.799 & 0.796 & 0.793 & 0.791 & 0.791 \\
\hline 0.22 & 0.719 & 0.713 & 0.707 & 0.704 & 0.701 \\
\hline 0.28 & 0.640 & 0.631 & 0.623 & 0.618 & 0.613 \\
\hline 0.33 & 0.563 & 0.551 & 0.542 & 0.534 & 0.529 \\
\hline 0.39 & 0.487 & 0.473 & 0.463 & 0.454 & 0.448 \\
\hline 0.44 & 0.413 & 0.399 & 0.388 & 0.379 & 0.372 \\
\hline 0.50 & 0.342 & 0.328 & 0.317 & 0.308 & 0.302 \\
\hline 0.56 & 0.275 & 0.262 & 0.252 & 0.244 & 0.238 \\
\hline 0.61 & 0.213 & 0.201 & 0.193 & 0.186 & 0.181 \\
\hline 0.67 & 0.157 & 0.148 & 0.141 & 0.135 & 0.131 \\
\hline 0.72 & 0.109 & 0.102 & 0.096 & 0.093 & 0.090 \\
\hline 0.78 & 0.068 & 0.064 & 0.061 & 0.058 & 0.056 \\
\hline 0.83 & 0.038 & 0.035 & 0.033 & 0.032 & 0.031 \\
\hline 0.89 & 0.016 & 0.015 & 0.014 & 0.014 & 0.013 \\
\hline
\end{tabular}

For rigorous finite element simulations on all stiffness terms of SCCBs, the interested reader is addressed to the work presented by Yuksel [5]. In that study also, an empirical formula is proposed for the equivalent beam model consisting of two nodded prismatic beam elements representing SCCBs. The formulation includes the shear deformations and the shapes of the cross sections of SCCBs. The method is introduced in a simple format and coupled shear walls with SCCBs can easily be modeled by the equivalent frame method.

\section{Summary and conclusions}

The cross-sectional area of the coupling beam at the beam-wall connections is purposely reduced by slit application. A series of shear stiffness analysis of SCCBs is carried out with the aid of the finite element method. The results obtained from the finite element analyses indicate significant decreases in shear stiffness force acting on the deep coupling beams due to slit existence at the ends. The height of the slits at the ends of the coupling beams is a significant parameter of the shear stiffness terms. As the height of the slits increases, the reduction in shear stiffness terms increases. The behavior of the coupling beams can be adjusted by applying the appropriate amount of slits at the ends of the coupling beams. Therefore, the designer can decrease the shear stiffness and the 
internal shear forces of the deep coupling beams effectively by introducing the appropriate amount of slits at the ends of the coupling beams without violating the architectural requirements.

\section{References}

[1] Kalkan, E. \& Yuksel, S.B., Prons and Cons of Multi-Story RC Tunnel Form Buildings. The Structural Design of Tall and Special Buildings, (in press).

[2] Yuksel, S.B. \& Kalkan, E., Behavior of Tunnel Form Buildings Under Quasi-Static Cyclic Lateral Loading. Structural Engineering and Mechanics, (in press).

[3] ACI 318-05., Building Code Requirements for Reinforced Concrete and Commentary. American Concrete Institute; Farmington Hills, MI., 2005.

[4] TSC. 1998., Specifications for the Structures to be Built in Disaster Regions. Ministry of Public Work and Settlement, Ankara, Turkey (Turkish Seismic Code 1998).

[5] Yuksel, S.B., Slit Connected Coupling Beams For Tunnel Form Building Structures. The Structural Design of Tall and Special Buildings, (in press).

[6] Chaallal, O., Gauthier, D. \& Malenfant, P., Classification methodology for coupled shear walls. Journal of Structural Engineering, ASCE, 122(12), pp. 1453-1458, 1996.

[7] Subedi, N.K., RC-coupled shear wall structures. II: Ultimate strength calculations. Journal of Structural Engineering, ASCE, 117(3), pp. 681697, 1991.

[8] Shiu, K.M., Takayanagi, T. \& Corley, G., Seismic behaviour of coupled wall system. Journal of Structural Engineering, ASCE, 110(5), pp. 10511066, 1984.

[9] Paulay, T. \& Priestly, M.J.N., Seismic Design of Reinforced Concrete and Masonry Buildings, John Wiley \& Sons: New York, 1992.

[10] Computer and Structures Inc. (CSI). 2002. SAP2000 User's Manual. Berkeley, CA, June 2002. www.csiberkeley.com.

[11] El-Mezaini, N., Balkaya, C. \& Citıpıoglu, E., Analysis of frames with nonprismatic members. Journal of Structural Engineering, ASCE. 117(6), pp. 1573-1592, 1991.

[12] Bathe, K.J., Finite Element Procedures, Prentice Hall Publisher: NJ, USA, 1996.

[13] Horrowitz, B., Singularities in elastic finite element analysis. Concrete International, December: pp. 33-36, 1997.

[14] Weaver W, Gere JM., Matrix Analysis of Framed Structures, Van Nostrand Reinhold: New York, 1990. 